\title{
Effect of dignity therapy model on stress, anxiety and depression of hemodialysis patients
}

\author{
Adeleh Mashayekhi Sardoo ${ }^{1}$, Abbas Abbaszade ${ }^{2}$, Hossein Rafiei ${ }^{3}$, Habibeh Mashayekhi Sardoo ${ }^{4}$, Fariba Borhani*5 \\ ${ }^{1}$ Department of Critical Care Nursing, Jiroft University of Medical Science, Jiroft, Iran \\ ${ }^{2}$ School of Nursing and Midwifery, Shahid Beheshti University of Medical Science, Tehran, Iran \\ ${ }^{3}$ Department of Medical Surgical Nursing, School of Nursing, Qazvin University of Medical Science, Qazvin, Iran \\ ${ }^{4}$ Faculty of Pharmacy, Azad University of Shahreza Branch, Shahreza, Isfahan, Iran \\ ${ }^{5}$ Medical Ethics and Law Research Center, Shahid Beheshti University of Medical Science, Tehran, Iran
}

Received: June 15, 2015

DOI: $10.5430 /$ ijh.v1n1p28
Accepted: August 5, $2015 \quad$ Online Published: August 14, 2015

URL: http://dx.doi.org/10.5430/ijh.v1n1p28

\begin{abstract}
Aim: Dignity therapy is a novel therapeutic approach to the treatment of psychological problems in patients under maintenance hemodialysis. The aim of this study was to determine the effects of dignity therapy model on stress, anxiety and depression of patients under maintenance hemodialysis.

Methods: In a randomised controlled trial conducted from December 2013 to March 2014 in one hemodialysis center in Iran, 42 patients under maintenance hemodialysis were randomly assigned into two groups (control and intervention group). Patients' level of stress, anxiety and depression were measured with using DASS-21 questionnaire before and one week after dignity therapy protocol implantation.

Results: Before implementation of dignity therapy protocol, level of stress, anxiety and depression were high and similar in patients in both groups $(p>.05)$. After implementation of dignity therapy protocol, level of stress, anxiety and depression significantly decreased in patients in dignity therapy group $(p>.05)$ but not in patients in control group $(p>.05)$.

Conclusions: Level of stress, anxiety and depression among hemodialysis patients is high. Dignity therapy is an effective intervention for decreasing stress, anxiety and depression in this group of patients.
\end{abstract}

Key Words: Dignity therapy, End stage renal disease, Maintenance hemodialysis, Psychological disorders

\section{INTRODUCTION}

Dignity is complex and multi-faceted, relating to feelings, control, presentation of self, privacy and behavior from others. $^{[1]}$ The notion of dignity is used to mark a threshold, a kind of respect and care beneath which the treatment of any human being should never fall. ${ }^{[2]}$ Similar to equality, diversity and humanity, dignity is basic rights for all individuals. ${ }^{[3]}$ All human beings are equal in dignity irrespective of gender, age, social status or ethnicity. Human dignity is probably one of the most important principles of bioethics. ${ }^{[2]}$ Finding from previous studies showed that undermining of dignity have relationship with depression, anxiety, desire for death, hopelessness, feeling of being a burden on others, and lower level of quality of life. ${ }^{[4-7]}$

When a patients' needs maintenance hemodialysis therapy, level of physical, mental, social and financial stress may in-

${ }^{*}$ Correspondence: Fariba Borhani; Email: Ghehsare21@ gmail.com; Address: Medical Ethics and Law Research Center, Shahid Beheshti University of Medical Science, Tehran, Iran. 
crease significantly, leading to an increased chance of psychiatric disorders development in this group of patients. ${ }^{[8]}$ Most previous studies reported that rate of psychiatric disorders such as depression, anxiety and stress among hemodialysis patients is high. ${ }^{[8-10]}$ In a study in 2014, Anjomshoa et al., examined the prevalence of depression in 217 patients undergoing hemodialysis using Beck Depression Inventory in Kerman, Iran. They found that approximately $86 \%$ of hemodialysis patients had some levels of depression. ${ }^{[8]}$ In another study; Ahmadzadeh and Mehdi reported the prevalence of depression, anxiety and psychosis in hemodialysis patients $50 \%, 12.2 \%$ and $0 \%$, respectively. ${ }^{[11]}$ Iran is a Middle East developing country with about 78 million residents. In Iran, there was a discrepancy in the availability of different renal replacement therapies, since the beginning of hemodialysis goes back to more than 36 years ago, while peritoneal dialysis and kidney transplantation have been systematically available from 17 and 30 years ago, respectively. ${ }^{[12]}$ In Iran all hemodialysis patients belong to a group of patients called "patients with special diseases" and are eligible for government-provided medical insurance. ${ }^{[12]}$

Dignity therapy is a novel therapeutic approach to the treatment of psychological problems for patients who suffer from life-threatening illnesses such as patients with chronic renal failure who are under maintenance hemodialysis. ${ }^{[13]}$ In present study, we examined the effect of dignity therapy on level of depression, anxiety and stress among patients who needs maintenance hemodialysis.

\section{MethodS}

This study is a randomised controlled trial conducted from December 2013 to March 2014 in one hemodialysis center, Jiroft, Iran. This study has received permissions from deputy of medical research and also the ethics' board of the Jiroft University of Medical Sciences.

Patients were eligible for the study if they aged 18 years and older, year on hemodialysis more than 1 year, with no previous history of psychiatric disorder and psychotropic drug use (with or without physician prescription) and ability to communicate. Addicted patients were excluded. Forty two patients were selected from accessible population and were then randomly put into two groups, control group and intervention group, by the supervisor of the hemodialysis center, who chose the next serially numbered sealed opaque envelope containing a simple 1:1 randomization sequence. Before the implementation of the protocol, the research methodology of the study was explained to all the patients and written consent was obtained. All participants were promised that all data would remain anonymous, kept confidential and be

Published by Sciedu Press stored safely.

Dignity therapy led by researcher (AM) who trained in this regards. Dignity Therapy protocol used in present study was developed by Harvey Max Chochinov. Patients were shown the framework of questions for dignity therapy (this was similar to questions used by Chochinov et al. ${ }^{[14]}$ ) and asked to consider what they might wish to speak about during their session(s); this initial introduction to, and explanation of dignity therapy took about one hour. The questions framework provides a flexible guide for the researchers delivering the therapy to shape the interview, based on patients' level of interest and responses. Within a few days, second meeting arranged; the researcher used the questions framework to help elicit patients recollections, hopes, wishes for loved ones, lessons learned, and things they wanted remembered by those they were about to leave behind. All therapy sessions were tape-recorded; these sessions usually took about one hour. On completion, the audio recording was transcribed verbatim and the transcript edited, to provide a clear and readable narrative. This transcript or generativity document was returned to the patient within about 4 working days from their previous session, read to them in its entirety to ensure that no errors of omission or commission needed to be addressed (this final session usually took about $30 \mathrm{~min}$ ). The final version of the generativity document was given to the patient, to share with anyone they choose. ${ }^{[15,16]}$

Patients' level of stress, anxiety and depression measured with using DASS-21 questionnaire before and one week after dignity therapy protocol implantation. The DASS-21 was developed by Lovibond and Lovibond and is a 21-item self report instrument designed to measure the three related negative emotional states of depression, anxiety and stress. ${ }^{[17]}$ Validity and reliability of Iranian version of DASS-21 were determined in good level by previous study (chronbach alpha $0.77,0.79$ and 0.78 for depression, anxiety and stress domain respectively). ${ }^{[18]}$

Data were analyzed with descriptive statistics and chi-square, paired $t$ test and independent $t$ test using statistical software SPSS 19 (SPSS Inc., Chicago, USA). The threshold of statistical significance was set at $p<.05$.

\section{RESUlts}

Of the 42 patients, $29(69 \%)$ were men and the rest were women. The mean age of all patients was $56.6 \pm 17.1$ years (range between 18-89 years). The demographic characteristics including age, race, sex, marital status, occupation, education level and duration of illness were similar in two groups $(p>.05)$. 


\subsection{Information about patients' level of stress}

Mean score of stress in patients in control group and dignity therapy group before intervention was $10.09 \pm 5.01$ and 9.49 \pm 5.47 respectively. According to results of independent $t$ test this difference between two groups were not statistically significant $(p=.683)$. Mean score of stress in patients in control group and dignity therapy group before intervention was $8.76 \pm 5.10$ and $5.61 \pm 4.92$ respectively. According to results of independent $t$ test this difference between two groups were statistically significant ( $p=.049$ ). Table 1 showed more information about patients' level of stress before and after intervention in both groups.

\subsection{Information about patients' level of anxiety}

Mean score of anxiety in patients in control group and dignity therapy before intervention was $6.71 \pm 4.82$ and 6.81 \pm 5.54 respectively. According to results of independent $t$ test this difference between groups were not statistically significant $(p=.953)$. Mean score of anxiety in patients in control group and dignity therapy before intervention was $6.47 \pm 5.34$ and $3.09 \pm 3.17$ respectively. According to results of independent $t$ test this difference between groups were statistically significant $(p=.017)$. Table 1 showed more information about patients' level of anxiety before and after intervention in both groups.

\subsection{Information about patients' level of depression}

Mean score of depression in patients in control group and dignity therapy before intervention was $8.19 \pm 4.33$ and 7.33 \pm 5.30 respectively. According to results of independent $t$ test this difference between groups were not statistically significant $(p=.569)$. Mean score of depression in patients in control group and dignity therapy before intervention was $7.09 \pm 4.97$ and $4.01 \pm 4.66$ respectively. According to results of independent $t$ test this difference between groups were statistically significant $(p=.044)$. Table 1 showed more information about patients' level of depression before and after intervention in both groups.

Table 1. Mean an standard deviation of psychological symptoms among hemodialysis patient before and after intervention

\begin{tabular}{|c|c|c|c|c|c|c|c|c|c|}
\hline & \multicolumn{2}{|c|}{ Depression } & \multirow[b]{2}{*}{$\begin{array}{l}p \\
\text { value }\end{array}$} & \multicolumn{2}{|c|}{ Anexity } & \multirow[b]{2}{*}{$\begin{array}{l}p \\
\text { value }\end{array}$} & \multicolumn{2}{|c|}{ Stress } & \multirow[b]{2}{*}{$\begin{array}{l}p \\
\text { value }\end{array}$} \\
\hline & $\begin{array}{l}\text { Before } \\
\text { intevention }\end{array}$ & $\begin{array}{l}\text { After } \\
\text { intervention }\end{array}$ & & $\begin{array}{l}\text { Before } \\
\text { intevention }\end{array}$ & $\begin{array}{l}\text { After } \\
\text { intervention }\end{array}$ & & $\begin{array}{l}\text { Before } \\
\text { intevention }\end{array}$ & $\begin{array}{l}\text { After } \\
\text { intervention }\end{array}$ & \\
\hline $\begin{array}{l}\text { Control } \\
\text { group }\end{array}$ & $8.1 \pm 4.3$ & $7.1 \pm 4.9$ & $>.05$ & $6.7 \pm 4.8$ & $6.4 \pm 5.3$ & $>.05$ & $10.1 \pm 5.1$ & $8.7 \pm 5.1$ & $>.05$ \\
\hline $\begin{array}{l}\text { Interventi } \\
\text { on group }\end{array}$ & $7.3 \pm 5.3$ & $4.1 \pm 4.6$ & $<.01$ & $6.8 \pm 5.5$ & $3.1 \pm 3.1$ & $<.01$ & $9.4 \pm 5.4$ & $5.6 \pm 4.9$ & $<.04$ \\
\hline$p$ value & $>.5$ & $<.04$ & & $>.5$ & $<.01$ & & $>.05$ & $<.04$ & \\
\hline
\end{tabular}

\section{Discussion}

Despite attention to dignity therapy is growing in medical and health researches; little attention has been to this in patients under maintenance hemodialysis. In present study we examined the effect of dignity therapy on the level of depression, anxiety and stress in patients under maintenance. Finding of present study showed that dignity therapy have positive effects to decreasing level of depression, anxiety and stress in this group of patients.

Results from the most previous studies indicated that psychological disorders such as depression, anxiety and stress are highly prevalent in hemodialysis patients. ${ }^{[8-11]}$ These common psychological disorders may negatively affect on the quality of life in patients and their response to treatment. ${ }^{[8]}$ In one study in this regards, Lopes et al., examined depression and these effects on hemodialysis patients in the United States and Europe. Results of Lopes et al., study showed that rate of withdrawal from maintenance dialysis is higher in depressed in compared to non depressed patients. Results of Lopes et al., study also showed that risk of mortality and hospitalization is highest among depressed patients. ${ }^{[10]}$ For this reasons, many studies conducted to test several pharmacological and non pharmacological methods to decreasing rate of depression, anxiety and stress in patients under maintenance hemodialysis. In one study in this regards, Duarte et $a l$., examined the effect of cognitive behavioral group therapy on depressed patients under hemodialysis. Results of Duarte et al., study showed that cognitive behavioral group therapy is an effective treatment for depressed patients under hemodialysis. ${ }^{[19]}$

During recent decades, due to the advancement of expertise and medical technology, patients with End Stage Renal Disease (ERDS) tend to live longer. Patient with ERDS who needs maintenance hemodialysis therapy usually live in ill health, and are frequently confronted with the physical and psychological deterioration, financial difficulties, loss of functional ability and dependency on both family members and health care workers. ${ }^{[13]}$ So they are vulnerable to loss 
of dignity. ${ }^{[13]}$ Loss of dignity may be increased the level of stress, anxiety and depression in hemodialysis patients. This problem among hemodialysis patients in developing countries with limited medical resources such as Iran is more prevalent. Most of the previous studies related to dignity therapy have focused on issues related to end of life and study about dignity therapy in hemodialysis patients is very limited. In present study we found that dignity therapy as a non pharmacological method has positive effect on decreasing level of depression, anxiety and stress in hemodialysis patients. In one experimental study with pre and post tests design in 2013, Vaghee et al., examined the effect of dignity therapy on human dignity in patients with chronic renal failure undergoing hemodialysis with using Patient Dignity Inventory (PDI). Results of Vaghee et al., showed that dignity therapy increased hemodialysis patients significantly. ${ }^{[13]}$

\section{Conclusion}

Level of stress, anxiety and depression among hemodialysis patients is high. Dignity therapy is an effective intervention for decreasing stress, anxiety and depression in this group of patients. Further studies are necessary in other countries and other clinical settings.

\section{REFERENCES}

[1] Baillie L. Patient dignity in an acute hospital setting: A case study. International Journal of Nursing Studies. 2009; 46: 23-37. PMid: 18790477. http://dx.doi.org/10.1016/j.ijnurstu. 2008.08.003

[2] UNESCO, Casebook on Human Dignity and Human Rights, Bioethics Core Curriculum Casebook Series, No. 1. UNESCO: Paris; 2011. 144.

[3] Jackson A, Irwin W. Dignity, humanity and equality: principle of nursing practice A. Nursing Standard. 2011; 25(28): 35-37. PMid: 21488447. http://dx.doi.org/10.7748/ns2011.03.2 $5.28 .35 . c 8396$

[4] Chochinov HM, Hack T, McClement S, et al. Dignity in the terminally ill: An empirical model. Soc Sci Med. 2002; 54: 433-443. http://dx.doi.org/10.1016/S0277-9536(01) 00084-3

[5] Chochinov HM, Hack T, Hassard T, et al. Dignity in the terminally ill: A cross-sectional cohort study. Lancet. 2002; 360: 2026-2030. http://dx.doi.org/10.1016/S0140-6736(02) 12022-8

[6] Chochinov HM. Dignity-conserving care: A new model for palliative care. JAMA. 2002; 287: 2253. http://dx.doi.org/10.1001/j ama.287.17.2253

[7] Chochinov HM. Dignity and the eye of the beholder. J Clin Oncol. 2004; 22: 1336-1340. PMid: 15051784. http://dx.doi.org/10. $1200 / J C 0.2004 .12 .095$

[8] Anjomshoa F, Esmaeili-Abdar M, Rafiei H, et al. Depression among hemodialysis patients: a cross-sectional study in southeast of Iran. Int J Epidemiol Res. 2014; 1(1): 24-28.

[9] Momeni A, Najafi M, Seidaie H. Comparison of mood depression disorder (MDD) in dialysis patients versus kidney transplant patients. J Nephrol Ren Transplant. 2013; 5(1): 11-6.

[10] Lopes AA, Albert JM, Young EW, et al. Screening for depression in hemodialysis patients: Associations with diagnosis, treatment, and outcomes in the DOPPS. Kidney Int. 2004; 66: 2047-53. PMid: 15496178. http://dx.doi.org/10.1111/j.1523-1755. $2004.00977 . x$
[11] Ahmadzade GH, Mehdi M. The prevalence of depression, anxiety and psychosis among hemodialysis patients in Nour and Ali Asghar hospital in Isfahan. J Isfahan Med Sch. 2012; 29(162): 1.

[12] Aghighi M, Heidary Rouchi A, ZamyadiM, et al. Dialysis in Iran Iran J Kidney Dis. 2008; 2: 11-5. PMid: 19367003.

[13] Vaghee S, Rabbani Javadi A, Mazlom SR, et al. The effect of dignity therapy on human dignity in patients with chronic renal failure undergoing hemodialysis. Evidence base Care Journal. 2013; 3(7): 63-72.

[14] Chochinov HM, Kristjanson LJ, Breitbart W, et al. Effect of dignity therapy on distress and end-of-life experience in terminally ill patients: a randomised controlled trial. Lancet Oncol. 2011; 12(8): 75362. http://dx.doi .org/10.1016/S1470-2045(11) 70153-X

[15] Hall S, Chochinov H, Harding R, et al. A Phase II randomised controlled trial assessing the feasibility, acceptability and potential effectiveness of Dignity Therapy for older people in care homes: Study protocol. BMC Geriatrics. 2009; 9: 9. PMid: 19317898 http://dx.doi.org/10.1186/1471-2318-9-9

[16] Lovibond PF, Lovibond SH. The structure of negative emotional states: Comparison of the Depression Anxiety Stress Scales (DASS) with the beck depression and anxiety inventories. Behav Res Ther. 1995; 33(3): 335- 343. http://dx.doi.org/10.1016/0005-7 967 (94) $00075-\mathrm{U}$

[17] Hosseinrezaei H, Pilevarzadeh M, Amiri M, et al. Psychological symptoms in family members of brain death patients in intensive care unit in Kerman, Iran. Global Journal of Health Science. 2014; 6(2): 203-208. http://dx.doi.org/10.5539/gjhs.v6n2p203

[18] Sahebi A, Asghari MJ, Salari RS. Validation of depression, anxiety and stress scale (DASS-21) for an Iranian population. J. Iranian Psychologists. 2005; 1(4): 299-310.

[19] Duarte PS, Miyazaki MC, Blay SL, et al. Cognitive behavioral group therapy is an effective treatment for major depression in hemodialysis patients. Kidney Int. 2009; 76: 414-21. PMid: 19455196. http://dx.doi.org/10.1038/ki.2009.156 